\title{
Exercise-Based Muscle Development Programmes and Their Effectiveness in the Functional Recovery of Rotator Cuff Tendinopathy: A Systematic Review
}

\author{
Juan G. Dominguez-Romero $\mathbb{D}^{D}$, José J. Jiménez-Rejano $\mathbb{D}^{\text {, }}$, Carmen Ridao-Fernández \\ and Gema Chamorro-Moriana *D
}

check for

updates

Citation: Dominguez-Romero, J.G.; Jiménez-Rejano, J.J.; Ridao-Fernández, C.; Chamorro-Moriana, G.

Exercise-Based Muscle Development Programmes and Their Effectiveness in the Functional Recovery of Rotator Cuff Tendinopathy: A Systematic Review. Diagnostics 2021, 11, 529 https://doi.org/10.3390/ diagnostics11030529

Academic Editor: Chul-Hyun Cho

Received: 6 February 2021

Accepted: 13 March 2021

Published: 16 March 2021

Publisher's Note: MDPI stays neutral with regard to jurisdictional claims in published maps and institutional affiliations.

Copyright: (c) 2021 by the authors. Licensee MDPI, Basel, Switzerland. This article is an open access article distributed under the terms and conditions of the Creative Commons Attribution (CC BY) license (https:// creativecommons.org/licenses/by/ $4.0 /)$.
Research Group "Area of Physiotherapy" CTS-305, University of Seville, 41009 Seville, Spain; j_gab_dom@hotmail.com (J.G.D.-R.); jjjimenez@us.es (J.J.J.-R.); mcrf.2817@gmail.com (C.R.-F.)

* Correspondence: gchamorro@us.es

\begin{abstract}
Background: Rotator cuff (RC) tendinopathy causes pain and functional limitation of the shoulder. Physical exercises are effective therapies but there is no consensus on which exercise programme is the most appropriate. Objective: To analyze and compare the effectiveness of different intervention modalities-based exclusively on physical exercise muscle-development programs to improve shoulder pain and function in RC tendinopathy. (2) Methods: Systematic review (PRISMA) through a search in PubMed, WOS, PEDro, Cinahl, Scopus and Dialnet. The PEDro Scale and the Cochrane Risk of Bias analyzed the methodological quality. A pre-established table collected data on: patients, interventions, outcome measures and results. A narrative synthesis of the results was conducted. (3) Results: eight articles were selected (Cochrane: low risk of bias; PEDro: good quality). All assessed programs were effective. Only one study found statistically and clinically significant differences in favour of eccentric training. The exercises used were: eccentric/concentric/conventional, open/closed kinetic chain, with/without co-activation of glenohumeral muscle, with/without pain, and in clinic/at home. (4) Conclusions: All exercise programs were effective in RC tendinopathy, improving pain and shoulder function. No solid results were obtained when the interventions were compared due to their heterogeneity. Patients perception assessment tools were the most widely used. Amount of load applied should be considered.
\end{abstract}

Keywords: physiotherapy; rotator cuff; tendinopathy; exercise; resistance training

\section{Introduction}

Shoulder pain is one of the most common symptoms of musculoskeletal injuries, and a quarter of the general population and up to two-thirds of adults suffer from it at some point in their lives [1]. Its prevalence has been estimated at $15-30 \%$ of the population [2]. The most common cause of shoulder pain is rotator cuff (RC) tendinopathy [3]. This structure surrounds the shoulder and is composed of the supraspinatus, infraspinatus, subscapularis, teres minor and long portion of the brachial biceps [4], although some authors do not include the latter $[5,6]$. In general, tendinopathies are common "overuse" injuries and are characterised by load-related pain and loss of function [7]. A 2019 symposium on tendinopathies [8], considered the terms "subacromial pain syndrome (or impingement)" and "rotator cuff-related shoulder pain" referring to pain in the shoulder tendons with loss of function, to be synonyms. The symptomatology of this pathology includes: minimal pain at rest with a broadly preserved range of motion (ROM) and increased pain in resistance training [1]. Evidence shows that disability caused by RC tendinopathy has a significant impact on daily life and can lead to a social burden due to absenteeism and health resource costs [9]. Half of those affected experience these problems for more than 12 months continuously and often end up undergoing surgery [10]. 
The tendency is to consider that the aetiopathological mechanism of RC tendinopathy is produced by acute and chronic changes in the tendon structure (increase and changes in collagen, proteoglycans, vascularization and cells), as well as in the surrounding bursa (increase in inflammatory proteins: pain mediators and bursa matrix modifiers) [11]. Despite this, both the aetiology and physiopathology of this tendinopathy, as well as its relationship with the subacromial bursa, should be studied further [11]. It is a multifactorial lesion combining intrinsic, extrinsic and environmental factors [11]. Lewis [12] considered that $\mathrm{RC}$ tendinopathy could be adjusted to the continuum model of tendinopathy of Cook et al. $[7,13]$, which sustained this pathology was dynamic and degenerative. It implied three phases: reactive, failed healing (known as the dysrepair phase) and degenerative. All of them could be reversed apart from the degenerative phase. The natural history of this tendinopathy was not always favourable, and in the long term the results of physiotherapy interventions were often poor [1].

RC tendinopathy suffers from pathological changes similar to those of lesions in other tendons, such as the epicondyles [14], Achilles tendon [15] and patellar [16]. In all of these, physical exercise-based therapies have shown their usefulness in achieving functional recovery. In fact, previous studies [17-20] showed that a programme of physical activity with progressive overload is effective for RC tendinopathy. Different types of physical exercise are used: concentric, eccentric, proprioceptive, high-load, etc. In addition, they could be directed at different structures, such as the cuff or the scapular muscles. Yet there is no consensus on which exercise programme is the most appropriate, since several authors show contradictory results [21-24]. On the other hand, even if this type of therapy modality (physical exercise) has been proven effective for the $\mathrm{RC}$, numerous systematic reviews $[17,25-28]$ insist on the need to improve the methodological quality of the studies to reach sound conclusions.

Given the current lack of knowledge as to which exercise programme is more effective in treating RC tendinopathy, knowing that this activity is an effective therapy; its high prevalence; and the fact that this pathology entails heavy spending, either on health care or in work terms; this study aimed to analyse and compare the effectiveness of different intervention modalities-based exclusively on physical exercise muscle-development programmes to improve shoulder function and pain in $\mathrm{RC}$ tendinopathy patients.

\section{Materials and Methods}

This systematic review followed the guidance of the PRISMA statement [29]. The protocol was published on PROSPERO with registration number CRD42020220098.

\subsection{Search Strategy}

A search was performed from inception through 31 December 2020 on six electronic databases: PubMed, WOS, PEDro, Cinahl, Scopus and Dialnet. Medical subject headings $(\mathrm{MeSH})$ terms were employed. Other terms of interest were also included due to its frequency in scientific studies. "Search strategy terms ordered by meaning" and "Search strategy in the different databases" are shown in Tables A1 and A2 (Appendices A and B), respectively.

\subsection{Study Selection and Inclusion Criteria}

- Participants: Adults ( $\geq 18$ years) with signs and symptoms compatible with RC tendinopathy in the absence of other shoulder diagnoses (ruptures/tears RC, frozen shoulder, shoulder instability).

- Intervention/comparison: Studies that include and compare programmes of active physical exercise involving gravity-resistance, either actively and freely or with an extra load applied (dumbbells, elastic bands, pulleys, etc.). Programmes consisting exclusively of active exercises (excluding manual therapy, electrotherapy, pharmacology, etc.) were allowed. Two exceptions are considered: passive stretching, as we understand that they usually form part of these programmes for final relaxation 
purposes; and the use of corticosteroids up to 2 months before the intervention, since most studies allowed this.

- Measurements: Studies that include measurements of shoulder strength and ROM, as well as of patients' perception, i.e., "Patient Reported Outcome Measures" (PROMs), of pain and function by means of functional assessment scales.

- Study design: Randomised Clinical Trials (RCTs) with a minimum of 6 points on the PEDro scale [30].

- Language: English.

\subsection{Data Extraction}

Data extraction was carried out by one reviewer (JD) and checked for accuracy by a second reviewer (CR). Disagreements were resolved by a third reviewer (GC). A preestablished table was used to detail the information on study characteristics: identification, objectives, participant characteristics (gender, age and inclusion/exclusion criteria), interventions, outcome measures and results of the selected studies.

\subsection{Methodological Quality Analysis}

Included studies were assessed for methodological quality using Physiotherapy Evidence Database (PEDro) critical appraisal tool. This method is valid and reliable for evaluating the internal validity of the studies [30]. PEDro consists of 11 items, although criterion 1 refers to the external validity of the paper and is excluded from the final result. Each criterion can be Yes (1 point) or No (0 points), with a maximum punctuation of 10 . A total score of 6 or more is considered to be a good methodological quality (6-8 good; 9-10 excellent), and a total score of 5 or less is related to a limited methodological quality [31]. This valuation was complemented using Cochrane Risk of Bias Tool (CROB). It consists of six domains with the following score: high risk, low risk and unclear risk [32].

\section{Results}

\subsection{Literature Search and Selection}

The literature search identified 885 records, of which 314 were duplicates. After screening the titles, abstracts and full text of the remaining 571 studies, 563 papers were excluded, and 8 papers were included in the review. Figure 1 shows the search and study selection process following PRISMA statement [29].


Figure 1. PRISMA flow diagram.

\subsection{Characteristics of Included Studies}

A detailed summary of the characteristics of each study can be found in Table 1. 
Table 1. Characteristics of studies




Table 1. Cont.

\section{Characteristics of Studies}

Study/Objective

Granviken, F. et al., 2013 [35]

Study objective:

To compare the different effects of home clise

Level of evidence: Therapy, 1b (OCEBM)

\section{Characteristics of Participant}

\section{$n=46$}

Sex: 24 men $/ 22$ women

Age (mean $\pm \mathrm{SD}$ ):

- $\quad$ Group 1: 48.2 (9.8) years

- Group 2: 47.6 (10.0) years

Inclusion criteria: Patients aged between 18-65 years; unilateral shoulder pain $>12$ (painful arc between 60 and $120^{\circ}$ during active ABD; infraspinatus and

Hawkins-Kennedy test.)

Exclusion criteria: Glenohumeral instability acromioclavicular joint pathology; labru pathology on imaging; full-thickness RC tears; glenohumeral osteoarthritis; undergone shoulder surgery; insufficien language capability; cervical spine problems; rheumatoid arthritis;other

Chaconas, E. J. et al., 2017 [36]

Study objective:

To compare outcomes, for individuals diagnosed with subacromial pain syndrom performing a 6 -week protocol of eccentric training of the shoulder external rotators compared to a general exerce protocol. at the insertion of the supraspinatus or $n=48$

Sex: 28 men $/ 20$ women

Age (mean \pm SD): $46.8 \pm 17.29$ years Inclusion criteria: $\geq 3$ positives tests of: Nee Hawkins-Kennedy and the empty can test; pain with resisted ER; palpable tenderness infraspinatus; painful are between 60-120 active $A B D$; shoulder pain $\geq 3$ month

Exclusion criteria: Red flags; full thicknes coultis and history of shoulder surgery.
Intervention/Comparison

Both groups:

Education in shoulder injuries (anatomy and RHB processes) Scapular stabilization, RC and mobility exercises without pain Stretching exercises

Frequency and duration: 2 times/day for 6 weeks.

Parameters: $3 \times 30$ rep

Group 1 -Home exercises $(n=23)$

1 supervised treatment + home exercises.

Group 2-Supervised exercises $(n=23): 10$ supervised treatments + home exercises

Eccentric vs. general shoulder exercises:

Both groups:

Diary exercise

- Scapular retraction:

Frequency: 1 time per day. Parameters: $2 \times 10$ rep.

- Posterior shoulder stretching:

$$
\begin{aligned}
& \text { - } \quad \text { Frequency: } 1 \text { time per day. } \\
& \text { - } \quad \text { Parameters: } 3 \times 30-45 \text { seg. }
\end{aligned}
$$

Duration: 6 week

Group 1-Eccentric exercises $(n=25)$ : Eccentric exercises with scapula retraction + posterior shoulder stretching.

- $\quad$ Eccentric exercises of external rotators:

- $\quad$ Frequency: 1 time per day. Parameters: $3 \times 15$ rep.

Group 2-General exercises $(n=23)$ : Shoulder general exercises protocol (flexion, $\mathrm{ABD}$, active scapular retraction and posterior shoulder stretching).

- $\quad$ Active ROM:

Frequency: 1 time per day
Outcome Measures/Results

Variables evaluated at 6 and 26 weeks

Main variable evaluated with:

SPADI

Secondary variables evaluated with

NPRS

Clinic test (painful arc, infraspinatus and Hawkins-Kennedy test)

FABQ

Digital inclinometer (shoulder AROM in flexion, ABD, ER and

cale to measure self-reported work statu

There was no statistically significant difference between home and supervised exercises in SPADI at 6 weeks (MD 0 points; $95 \%$ CI $(-14,14)$ and 26 weeks (MD -2 points; $95 \% \mathrm{CI}(-21,17)$ of follow-up.

There were no significant differences between groups in pain, physical

activity, or work on the FABQ and ROM. No participant reported full
recovery in terms of perceived benefit. One subject was dissatisfied with (n)

Variables evaluated at 3,6 weeks and 6 months.

Main variables evaluated with:

- WORC

Secondary variables evaluated with:

- Dynamometer (isometric strength of shoulder in ABD, ER and IR) - $\quad$ GRYB

After 3 weeks only NPRS $(p<0.03)$ and the isometric strength in ER $(p<0.001)$ showed a statistically significant interaction effect. At the end of the treatment (6th week), a significant interaction was identified for the mean and worst values of NPRS $(p<0.001)$, the ER strength $(<0.001)$ and the proportions of external rotator to abductor and external rotator to internal rotator strengh $(p<0.04)$. After 6 months, secondary outcomes improved for pain on average and pain on worst $(p<0.02)$, ABD UQYBT and stength ratios were not statistically significant in the multilevel model after 6 months. 
Table 1. Cont.

\section{Characteristics of Studie}

Study/Objective

Heron, S. et al., 2017 [23] Study objective:

To assess the efficacy of three different excise programmes in treating RC

syndrome.

Level of evidence: Therapy, $1 \mathrm{~b}$ (OCEBM)

\section{Characteristics of Participant}

$n=120$

Sex: $71 \mathrm{men} / 49$ women

Inclusion criteria: shoulder pain for $\geq 3$

months: no passive limitation of ROM

suggestive of adhesive capsulitis; pain on

isometric RC testing; pain on

Hawkins-Kennedy or empty can tests; able

to read and write English.

Exclusion criteria: symptoms of cervical

radiculopathy; diagnosed inflammatory

disorder; neurological disorder; widesprea

pain condition; complete RC tear (positive

drop arm test and/or Oxford scale grade II

$n=36$

Sex= 19 men $/ 17$ women

Age (mean $\pm \mathrm{SD}$ )

- $\quad$ Group $1=50.2 \pm 10.8$ year

- $\quad$ Group $2=48.6 \pm 12.3$ years

Inclusion criteria: $18-65$ years; both genders; unilateral subacromial pain $\geq 3$ months;

Dejaco, B. et al., 2017 [24]

Study objectiv

To investigate the effectiveness of isolated eccentric versus conventional exercise terapy in patients with RC tendinopathy. out of 3 positive impingement tests (empty-can, Hawkins-Kennedy and modified Neer test).

Exclusion criteria: Subjective feeling of instability and positive apprehension sign; positive scapular assistance and / $\mathrm{o}$

resistance test; partial/full ruptures of RC; calcifications $>4$ mma, acromion type history of shoulder fracture and/or should surgery; cervical radiculopathy; adhesive capsulitis; systemic diseases; corticosteroid injection 3 months prior to inclusion.
Intervention/Comparison

Open kinetic chain vs. closed kinetic chain vs. mobility exercises

All groups:

Anterior and posterior shoulder stretching ( $5 \mathrm{rep} / 2$ times per

- Frequency and duration: 2 times/day during 6 weeks.

- Parameters: $3 \times 10$ rep.

Group 1-Open kinetic chain exercises $(n=40)$ :

$E R, I R$ and $A B D$ exercises with a resistance elastic band.

presition

列

R, ER and $A B D$ exercises from self-passive mobility to free active mobility.

Eccentric vs. conventional exercises

Both groups: 1 session of physiotherapy per week (during the first

6 weeks) and 3 sessions per week (during the last 6 weeks)

- Frequency and duration: Diary home exercises during 12 weeks. Paran

- Stretching: Minor pectoral and cross ADD for posterior shoulder musculature and capsule structures.

Group 1-Eccentric exercises $(n=20): 2$ differents exercises 2 times/day.

ER in supine with shoulder $90^{\circ} \mathrm{ABD}$

1. $\quad \mathrm{ABD}$ in scapular plane until $90^{\circ}$ (eccentric phase)

Group 2-Conventional exercises $(n=16): 8$ differents exercises time/day

ABD "full can" in scapular plane until $90^{\circ}$.

IR and ER at $0^{\circ}$

Shoulder shrugs

Horizontal ABD in prone position with ER.

\section{Outcome Measures/Results}

Variables evaluated at 6 weeks.

Main variable evaluated with

SPADI

All groups showed a significant reduction in SPADI over the 6 week follow-up

Change of intra-group mean in SPADI; (Effect size). Group 1: 12; $p=0.0001$ (0.56); Group 2: 9; $p=0.0002$ (0.63); Group 3: 9; $p=0.0002$

(0.49).

There were no significant differences between groups.

(Kruskal-Wallis test): Change in SPADI mean $(95 \% \mathrm{CI})$ : Group 1: -3.5

There were no clinically significant differences in SPADI during follow-up.

Variables evaluated at 6,12 and 26 weeksMain variable evaluated with: $\mathrm{CM}$

The score increased significantly in both groups ( $0-26$ weeks). Group 1:


significant differences between groups (4.6 points)

VAS

The score improved significantly in both groups. Group $1:-19.9 \mathrm{~mm}(p$ $<0.001)$ and Group 2: $-22.3 \mathrm{~mm}(p<0.001)$. There were no significant differences between groups $(2.4 \mathrm{~mm})$.

- $\quad$ Goniometer (shoulder ROM in flexion-elevation, ABD-elevation and ER)

Dynamometer (isometric strength of shoulder ABD)

Each group obtained a slight improvement in ROM and isometric

trength at 26 weeks. No statistically significant differences were found either intra- or inter-group. 
Table 1. Cont.

\section{Characteristics of Studie}

Study/Objective

Vallés-Carrascosa, E. et al., 2018 [22] Study objective:

To compare the effect on pain, active ROM and shoulder function of an exercise protocol performed with pain $<40 \mathrm{~mm}$ Visual Analogue Scale and without pain, in patients with subacromial syndrome.
Level of evidence: Therapy, $2 \mathrm{~b}$ (OCEBM)

$\begin{array}{ll} & \text { chro } \\ & n=4 \\ \text { Sex: } & \end{array}$

\section{Bourdreau, N. et al., 2019 [37]}

Study objective:

short-term efficacy of

adding glenohumeral adductor coactivation to a RC strengthening program to improve acromiohumeral distance in adults with RC tendinopathy.

Level of evidence: Therapy, $1 \mathrm{~b}$ (OCEBM)

\section{Characteristics of Participant}

$n=22$

Sex: $10 \mathrm{men} / 12$ women

Age (mean (1st quartile; 3rd quartile))

- $\quad$ Group 1: $60.0(47.0 ; 70.0)$ years

- Group 2: $57.0(49.0 ; 70.0)$ years

Inclusion criteria: $25-70$ years; referred to rehabilitation services after a diagnosis of
subacromial syndrome; painful arc upon active lifting of the upper limb (ABD: $60^{\circ}-120^{\circ}$ )

Exclusion criteria: RC tears; shoulder

shoulder; shoulder prosthesis; fibromyalgi (n)

$n=42$

20 men/22 women

Age (mean $\pm \mathrm{SD})$ :

- $\quad$ Group 1: $49.6 \pm 13.2$ years

Inclusion criteria: $18-65$ years; symptoms

lasting >1month; a painful arc in active

flexion or ABD; positive Neer or Hawkin's Kennedy test; pain when resisting humeral ER or ABD; English or French languages. Exclusion criteria. Full-thickness RC tear, shouldert surgery, shouldic capsulitis,

rheumatoid arthritis: systemic inflammatory

or neurologic condition; corticosteroid

injections in the affected shoulder within the past 6 weeks.
Intervention/Comparison

With vs. withouth pain

Both groups:

- $\quad$ RC exercises (in the affected limb), scapular stabilization exercises

(both limb) and upper limb stretching (both limbs).

Frequency and duration: 5 times/week during 4 weeks. (The

stretchings were performed 3 times/session

Group 1-With pain $(n=11)$ : Exercises with pain (no $>40 \mathrm{~mm}$ on the

VAS scale).

Group 2 -Without pain $(n=11)$ : Exercises without pain $(0 \mathrm{~mm}$ on VAS scale).

Exercises with co-activation of glenohumeral musculature vs. without it Both groups:

- Serratus anterior, trapezius and glenohumeral muscles (ER and

\section{IR) strengthening exercises}

Frequency and duration: 1 time/day-7 days/week—during 6 weeks.

Group 1-Co-activation of glenohumeral muscles $(n=21)$ :

Glenohumeral muscles exercises with recruitment of minor pectoral and done in the same way.

ivation of glenohumeral muscles $(n=21)$ and latissimus dorsi, with vises without recruitment of minor pectora were done in the same way.
Outcome Measures/Results

Variables evaluated at 4 weeks

Main variables evaluated with

- VAS

Goniometer (shoulder AROM in flexion, extension, ABD, ADD

Secondary variable evaluated with:

- $\mathrm{CM}$

Both groups improved significantly. VAS and CM improved

significantly $(p<0.01)$, as did AROM $(p<0.05)$.

There were no significant differences between groups $(p>0.05)$

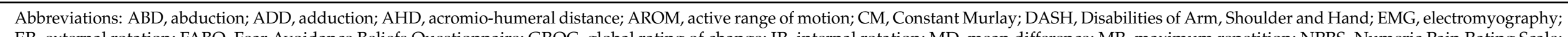

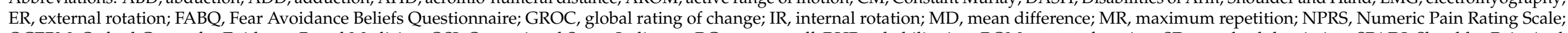

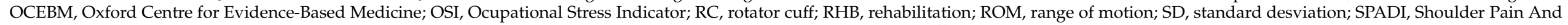
Disabilities Index; UQYBT, Upper Quarter Y-Balance test; VAS, Visual Analogue Scale; WORC, Western Ontario Rotator Cuff Index.
}

Variables evaluated at 3 and 6 weeks

Main variable evaluated with:

Secondary variables evaluated with:

- WORC

No statistically significant differences were obtained between groups for $\operatorname{DASH}(p=0.522)$, WORC $(p=0.421), \operatorname{VAS}(p=0.140)$ and AHD $(p<0.001)$ 


\subsection{Assessment of Methodological Quality}

The level of evidence of this systematic review is $1 \mathrm{~b}$ according to the CEBM Classification (Centre for Evidence-Based Medicine; Oxford) [38].

The results of the PEDro scale are shown in Table 2.

Table 2. Assessment of the methodological quality of the studies using PEDro scale.

\begin{tabular}{ccccccccccccc}
\hline \multirow{2}{*}{ Study } & \multicolumn{1}{c}{} & \multicolumn{1}{c}{ Criteria } & \multicolumn{1}{c}{ Total } \\
\cline { 2 - 14 } & $\mathbf{1}$ & $\mathbf{2}$ & $\mathbf{3}$ & $\mathbf{4}$ & $\mathbf{5}$ & $\mathbf{6}$ & $\mathbf{7}$ & $\mathbf{8}$ & $\mathbf{9}$ & $\mathbf{1 0}$ & $\mathbf{1 1}$ & \\
\hline Maenhout, A. et al. [33] & $\sqrt{ }$ & $\sqrt{ }$ & $X$ & $\sqrt{ }$ & $X$ & $X$ & $X$ & $\sqrt{ }$ & $\sqrt{ }$ & $\sqrt{ }$ & $\sqrt{ }$ & 6 \\
\hline Blume, C. et al. [34] & $\sqrt{ }$ & $\sqrt{ }$ & $\sqrt{ }$ & $\sqrt{ }$ & $X$ & $X$ & $\sqrt{ }$ & $\sqrt{ }$ & $\sqrt{ }$ & $\sqrt{ }$ & $\sqrt{ }$ & 8 \\
\hline Granvinken, F. et al. [35] & $\sqrt{ }$ & $\sqrt{ }$ & $\sqrt{ }$ & $\sqrt{ }$ & $X$ & $X$ & $\sqrt{ }$ & $\sqrt{ }$ & $\sqrt{ }$ & $\sqrt{ }$ & $\sqrt{ }$ & 8 \\
\hline Chaconas, E. J. et al. [36] & $X$ & $\sqrt{ }$ & $X$ & $\sqrt{ }$ & $X$ & $X$ & $\sqrt{ }$ & $\sqrt{ }$ & $X$ & $\sqrt{ }$ & $\sqrt{ }$ & 6 \\
\hline $\begin{array}{c}\text { Heron, S. et al. } \\
\text { [23] }\end{array}$ & $\sqrt{ }$ & $\sqrt{ }$ & $\sqrt{ }$ & $\sqrt{ }$ & $X$ & $X$ & $\sqrt{ }$ & $X$ & $\sqrt{ }$ & $\sqrt{ }$ & $\sqrt{ }$ & 7 \\
\hline Dejaco, B. et al. [24] & $\sqrt{ }$ & $\sqrt{ }$ & $\sqrt{ }$ & $\sqrt{ }$ & $X$ & $X$ & $X$ & $\sqrt{ }$ & $\sqrt{ }$ & $\sqrt{ }$ & $\sqrt{ }$ & 7 \\
\hline Vallés-Carracosa, E. et al. [22] & $\sqrt{ }$ & $\sqrt{ }$ & $\sqrt{ }$ & $\sqrt{ }$ & $X$ & $X$ & $X$ & $\sqrt{ }$ & $\sqrt{ }$ & $\sqrt{ }$ & $\sqrt{ }$ & 7 \\
\hline Bourdreau N. et al. [37] & $\sqrt{ }$ & $\sqrt{ }$ & $\sqrt{ }$ & $\sqrt{ }$ & $X$ & $X$ & $\sqrt{ }$ & $\sqrt{ }$ & $\sqrt{ }$ & $\sqrt{ }$ & $\sqrt{ }$ & 8 \\
\hline
\end{tabular}

Data extracted from PEDro database. Criteria: 1, Eligibility criteria were specified (not used for score); 2, Subjects were randomly allocated to groups; 3 , Allocation was concealed; 4 , Groups were similar at baseline regarding the most important prognostic indicators; 5 , There was blinding of all subjects; 6 , There was blinding of all therapists who administered the therapy; 7, There was blinding of all assessors who measured at least one key outcome; 8 , Measures of at least one key outcome were obtained from more than $85 \%$ of the subjects initially allocated to groups; 9 , All subjects for whom outcome measures were available received the treatment or control condition as allocated or, where this was not the case, data for at least one key outcome was analysed by 'intention-to-treat'; 10, The results of between-group statistical comparisons were reported for at least one key outcome; 11, The study provides both point measures and measures of variability for at least one key outcome). $\sqrt{ }$ criteria met; $X$ : criteria not met.

The results of the Cochrane Risk of Bias Tool are shown in Figure 2.

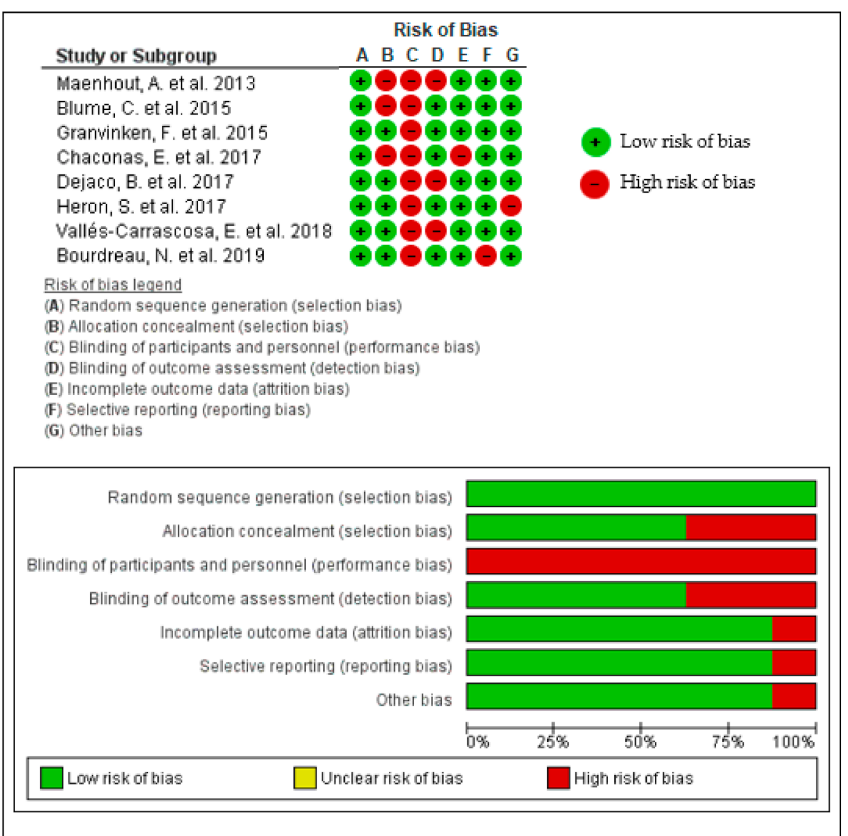

Figure 2. Assessment of the methodological quality of the studies using Cochrane Risk of Bias Tool for Randomised Trials (summary and graph).

In short, regarding PEDro, all studies showed good methodological quality (between 6 and 8 ), with a minimum score of 6 being an inclusion criteria. Despite the good score, it should be noted that none of the studies scored the items: "There was blinding of all 
subjects" 5 and "There was blinding of all therapists who administered the therapy" 6 . Conversely, the items "Subjects were randomly allocated to groups" 2, "Groups were similar at baseline regarding the most important prognostic indicators" 4 , "The results of between group-statistical comparisons were reported for at least one key outcome" 1 and "The study provides both points measures and measures of variability for at least one key outcome" 11 were scored by all studies.

Regarding CROB, all studies showed "low risk of bias". The domains "blinding of participants and personnel (performance bias)" was scored by no study and the "random sequence generation (selection bias)" was scored by all studies.

In general, the results obtained using the PEDro (good) were consistent with those of the CROB (low risk of bias).

\subsection{Participant Characteristics}

A total of 409 adult participants, 198 women and 211 men, were studied. The studies used a sample size between 18 [39] and 120 subjects [23].

As for the inclusion criteria of the papers, five of them $[23,24,33,35,36]$ established a symptom duration of at least 3 months. All the studies, except one [22], used orthopaedic shoulder tests to evaluate participants' inclusion in the study. Table 3 represents the different assessment tests used in the studies' inclusion criteria and how many times these tests were employed.

Table 3. Assessment procedures used in the selected studies.

\begin{tabular}{|c|c|c|c|c|c|c|}
\hline \multirow[b]{2}{*}{ Studies } & \multicolumn{6}{|c|}{ Assessment Tests } \\
\hline & $\begin{array}{c}\text { Hawkins- } \\
\text { Kennedy } \\
\text { Test }\end{array}$ & Neer Test & $\begin{array}{c}\text { Isometric } \\
\text { Test }\end{array}$ & Painful Arc & $\begin{array}{c}\text { Empty Can } \\
\text { Test }\end{array}$ & Others * \\
\hline $\begin{array}{l}\text { Maenhout, A. } \\
\text { et al. [33] }\end{array}$ & $\sqrt{ }$ & $\sqrt{ }$ & $\sqrt{ }$ & $\sqrt{ }$ & & $\sqrt{ }$ \\
\hline $\begin{array}{c}\text { Blume, C. et al. } \\
{[34]}\end{array}$ & $\sqrt{ }$ & $\sqrt{ }$ & & & & $\sqrt{ }$ \\
\hline $\begin{array}{c}\text { Granvinken, F. } \\
\text { et al. [35] }\end{array}$ & $\sqrt{ }$ & & $\sqrt{ }$ & $\sqrt{ }$ & & $\sqrt{ }$ \\
\hline $\begin{array}{c}\text { Chaconas, E. J. } \\
\text { et al. [36] }\end{array}$ & $\sqrt{ }$ & $\sqrt{ }$ & $\sqrt{ }$ & $\sqrt{ }$ & $\sqrt{ }$ & $\sqrt{ }$ \\
\hline $\begin{array}{l}\text { Heron, S. et al. } \\
{[23]}\end{array}$ & $\sqrt{ }$ & & $\sqrt{ }$ & & $\sqrt{ }$ & \\
\hline $\begin{array}{c}\text { Dejaco, B. et al. } \\
{[24]}\end{array}$ & $\sqrt{ }$ & $\sqrt{ }$ & & & $\sqrt{ }$ & \\
\hline $\begin{array}{c}\text { Vallés- } \\
\text { Carracosa, E. } \\
\text { et al. [22] }\end{array}$ & & & & $\sqrt{ }$ & & \\
\hline $\begin{array}{c}\text { Bourdreau N. } \\
\text { et al. [37] }\end{array}$ & $\sqrt{ }$ & $\sqrt{ }$ & $\sqrt{ }$ & $\sqrt{ }$ & & \\
\hline Total & 7 & 5 & 5 & 5 & 3 & 4 \\
\hline
\end{tabular}

* Coracoid extraction, sensitivity in tendon insertion of the supraspinatus or infraspinatus, Jobe's test, infraspinatus test.

\subsection{Characteristics of the Interventions}

The studies compared different muscle development exercise programmes involving gravity-resistance, either actively and freely or with an extra load applied (dumbbells, elastic bands, pulleys, etc.): concentric vs. eccentric exercises [34]; open kinetic chain vs. closed kinetic chain vs. mobility exercises [23]; exercises with co-activation of glenohumeral muscles vs. without it [37]; exercises with pain vs. without pain [22]; eccentric exercises vs. conventional therapeutic exercises, i.e., a typical exercise programme for RC tendinopathy [24,36]; exercises with high eccentric load vs. without it [33]; supervised exercises in 
clinic vs. exercises at home [35]. The studies were grouped according to the predominant muscle contraction: concentric, eccentric and both of them (Table 4).

Table 4. Grouping of studies according to muscle contraction mode.

\begin{tabular}{cc}
\hline Muscle Contraction Types & Number of Studies \\
\hline $\begin{array}{c}\text { Concentric + Eccentric } \\
\text { (The load is applied during the concentric and eccentric phase) }\end{array}$ & $4[22,23,35,37]$ \\
\hline $\begin{array}{c}\text { Concentric } \\
\text { (The load is only applied during the concentric phase) }\end{array}$ & $1[34]$ \\
\hline $\begin{array}{c}\text { Eccentric } \\
\text { (The load is only applied during the eccentric phase) }\end{array}$ & $4[24,33,34,36]$ \\
\hline
\end{tabular}

The content of the exercise programmes was heterogeneous, although in general it consisted of exercises with resistance bands, functional exercises (bending, standing up from a chair, etc.) and, despite the exclusivity, as an exception, passive stretching exercises. The interventions lasted from 4 [22] to 12 weeks $[24,33]$. Only three studies $[24,33,36]$ followed up patients until week 26 (Table 5).

Table 5. Duration and monitoring of the intervention.

\begin{tabular}{|c|c|c|c|c|c|c|c|c|c|}
\hline \multirow{10}{*}{ STUDIES } & \multirow{2}{*}{$\begin{array}{l}\text { Monitoring and Evaluation of } \\
\text { Variables }\end{array}$} & \multicolumn{8}{|c|}{ WEEKS } \\
\hline & & 0 & 3 & 4 & 5 & 6 & 8 & 12 & 26 \\
\hline & Maenhout, A. et al. [33] & $\sqrt{ }$ & & & \multicolumn{3}{|c|}{$\sqrt{ }$} & $\sqrt{ }$ & \\
\hline & Blume, C. et al. [34] & $\sqrt{ }$ & & & \multicolumn{2}{|l|}{$\sqrt{ }$} & $\sqrt{ }$ & & \\
\hline & Granvinken, F. et al. [35] & $\sqrt{ }$ & & & & \multirow{2}{*}{$\begin{array}{l}\sqrt{ } \\
\sqrt{ }\end{array}$} & & & $\sqrt{ }$ \\
\hline & Chaconas, E. J. et al. [36] & $\sqrt{ }$ & $V$ & & & & & & $\sqrt{ }$ \\
\hline & Heron, S. et al. [23] & $\sqrt{ }$ & & & & $\sqrt{ }$ & & & \\
\hline & Dejaco, B. et al. [24] & $\sqrt{ }$ & & & & $\sqrt{ }$ & & $\sqrt{ }$ & $\sqrt{ }$ \\
\hline & Vallés-Carrascosa, E. et al. [22] & $\sqrt{ }$ & & $\sqrt{ }$ & & & & & \\
\hline & Bourdreau, N. et al. [37] & $\sqrt{ }$ & $\sqrt{ }$ & & & $\sqrt{ }$ & & & \\
\hline
\end{tabular}

End of intervention; $\sqrt{ }$ : Time of evaluation of the variables.

\subsection{Outcome Measures of the Selected Studies}

Dynamometers were used to measure isometric muscular strength of the shoulder in $\operatorname{ABD}[24,33,34,36], \mathrm{ER}[33,34,36]$ and IR $[33,36]$. Digital inclinometers and goniometers were employed to measure shoulder ROM in flexion [22,24,35], extension [22], ABD [22,24,34,35], adduction [22], ER [22,24,35] and IR [22,35]. All the selected studies measured the patients' perception of pain, function, fear, etc., through PROMs (Table 6).

\subsection{Narrative Synthesis of the Results of the Selected Studies}

The results were presented on the basis of a comparison between the different exercise programmes used:

\section{- $\quad$ Concentric vs. eccentric training}

Based on one RCT ( $n=34$ ) [34] with a low risk of bias (PEDro scale), there were no significant differences when using exercise programmes with concentric or eccentric contractions for the improvement of shoulder pain, function, ROM and strength.

Based on one RCT $(n=120)$ [23] with low risk of bias (PEDro scale), there were no statistically significant differences between groups for improvement of shoulder pain and function, and no clinically relevant differences were found in the primary variable "Shoulder Pain and Disabilities Index" (SPADI).

- Open kinetic chain vs. closed kinetic chain vs. mobility exercises 
Table 6. PROMs used in selected studies.

\begin{tabular}{|c|c|c|c|c|c|c|c|c|}
\hline \multirow[b]{2}{*}{ Studies } & \multicolumn{8}{|c|}{ Patient Reported Outcome Measures } \\
\hline & NPRS/VAS & SPADI & WORC & DASH & $\mathrm{CM}$ & FABQ & UQYBT & GROC \\
\hline $\begin{array}{l}\text { Maenhout, A. et al. } \\
\text { [33] }\end{array}$ & & $\sqrt{ }$ & & & & & & \\
\hline Blume, C. et al. [34] & & & & $\sqrt{ }$ & & & & \\
\hline $\begin{array}{c}\text { Granvinken, F. et al. } \\
{[35]}\end{array}$ & $\sqrt{ }$ & $\sqrt{ }$ & & & & $\sqrt{ }$ & & \\
\hline $\begin{array}{c}\text { Chaconas, E. J. et al. } \\
\text { [36] }\end{array}$ & $\sqrt{ }$ & & $\sqrt{ }$ & & & & $\sqrt{ }$ & $\sqrt{ }$ \\
\hline Heron, S. et al. [23] & & $\sqrt{ }$ & & & & & & \\
\hline Dejaco, B. et al. [24] & $\sqrt{ }$ & & & & $\sqrt{ }$ & & & \\
\hline $\begin{array}{l}\text { Vallés-Carracosa, E. } \\
\text { et al. [22] }\end{array}$ & $\sqrt{ }$ & & & & $\sqrt{ }$ & & & \\
\hline $\begin{array}{c}\text { Bourdreau N. et al. } \\
{[37]}\end{array}$ & $\sqrt{ }$ & & $\sqrt{ }$ & $\sqrt{ }$ & & & & \\
\hline Total & 5 & 3 & 2 & 2 & 2 & 1 & 1 & 1 \\
\hline
\end{tabular}

Abbreviations: CM, Constant Murlay Score; DASH, Disabilities of Arm, Shoulder and Hand; FABQ, Fear Avoidance Beliefs Questionnaire; GROC, Global Rating of Change; NPRS, Numeric Pain Rate Scale; PROMs, Patients Related Outcome Measures; SPADI, Shoulder Pain and Disability Index; UQYBT, Upper Quarter YBalance test; VAS, Visual Analogue Scale; WORC, Western Ontario Rotator Cuff Index.

\section{- $\quad$ Exercises with vs. without co-activation of glenohumeral musculature}

Based on one RCT $(n=42)$ [37] with low risk of bias (PEDro scale), there were no statistically significant differences between groups for shoulder pain, function and acromiohumeral distance (AHD).

- $\quad$ Exercises with pain vs. without pain

Based on one RCT ( $n=22)$ [22] with a low risk of bias (PEDro scale), both exercise methodologies were seen to significantly improve shoulder pain, function and ROM without differences between them.

\section{- Eccentric training vs. conventional therapeutic exercises}

Based on 2 RCTs $(n=36)$ [24] and $(n=48)$ [36] with low risk of bias (PEDro scale), different results were found. While the first study found that both exercise methodologies improved shoulder pain and function significantly without finding differences between them, the second showed statistically and clinically relevant differences for pain and function using an eccentric exercise programme.

- $\quad$ Exercises with vs. without high eccentric load

Based on one RCT ( $n=61$ ) [33] with a low risk of bias (PEDro scale), it was argued that both methodologies significantly improved pain, function and strength, but no differences were found between them.

- $\quad$ Supervised exercises vs. exercises at home:

Based on one RCT ( $n=46$ ) [35] with low risk of bias (PEDro scale), there were no statistically significant differences between the two methodologies for the improvement of pain and function. No participant reported full recovery after treatment.

To summarize, the narrative synthesis showed, in relation to the effectiveness of the interventions, that only one study [36] found statistical and clinical significance between the groups (Table 7). 
Table 7. Interventions based on muscle development with load and their effectiveness based on the variables studied.

\begin{tabular}{|c|c|c|c|c|c|c|c|c|c|c|}
\hline & ROM & $\begin{array}{l}\text { ISOMETRIC } \\
\text { STRENGHT }\end{array}$ & SPADI & WORC & DASH & NPRS/VAS & $\mathrm{CM}$ & FABQ & UQYBT & GROC \\
\hline $\begin{array}{l}\text { Maenhout, A. } \\
\text { et al. [33] }\end{array}$ & & $\sqrt{ }$ & $\sqrt{ }$ & & & & & & & \\
\hline $\begin{array}{l}\text { Blume, C. } \\
\text { et al. [34] }\end{array}$ & $\sqrt{ }$ & $\sqrt{ }$ & & & $\sqrt{ }$ & & & & & \\
\hline $\begin{array}{l}\text { Granvinken, F. } \\
\text { et al. [35] }\end{array}$ & $\sqrt{ }$ & & $\sqrt{ }$ & & & $\sqrt{ }$ & & $\sqrt{ }$ & & \\
\hline $\begin{array}{l}\text { Chaconas, E. J. } \\
\text { et al. [36] }\end{array}$ & $\sqrt{ }$ & $\sqrt{ }$ & & $\sqrt{ }$ & & $\sqrt{ }$ & & & $\sqrt{ }$ & $\sqrt{ }$ \\
\hline $\begin{array}{c}\text { Heron, S. et al. } \\
\text { [23] }\end{array}$ & & & $\sqrt{ }$ & & & & & & & \\
\hline $\begin{array}{l}\text { Dejaco, B. } \\
\text { et al. [24] }\end{array}$ & $\sqrt{ }$ & $\sqrt{ }$ & & & & $\sqrt{ }$ & $\sqrt{ }$ & & & \\
\hline $\begin{array}{c}\text { Vallés- } \\
\text { Carrascosa, E. } \\
\text { et al. [22] }\end{array}$ & $\sqrt{ }$ & & & & & $\sqrt{ }$ & $\sqrt{ }$ & & & \\
\hline $\begin{array}{l}\text { Bourdreau, N. } \\
\text { et al. [37] }\end{array}$ & & & & $\sqrt{ }$ & $\sqrt{ }$ & $\sqrt{ }$ & & & & \\
\hline
\end{tabular}

Significant and effective; $\square$ Not significant. $\sqrt{ }$ Variable measured in study; Abbreviations: CM Constant Murlay; DASH, Disabilities of Arm, Shoulder and Hand; FABQ, Fear Avoidance Beliefs Questionnaire; GROC, Global Rating of Change; NPRS, Numeric Pain Rating Scale; OSI, Ocupational Stress Indicator; ROM, range of motion; SPADI, Shoulder Pain and Disabilities Index; UQYBT, Upper Quarter Y-Balance test; VAS, Visual Ananolgue Scale; WORC, Western Ontario Rotator Cuff Index.

\section{Discussion}

This systematic review analysed and compared the efficacy of different intervention modalities based exclusively on muscle-development physical exercise programmes for the improvement of shoulder pain and function in patients suffering from RC tendinopathy. Based on the results obtained, all therapeutic modalities of physical exercise improved both variables in a similar way, without highlighting the effectiveness of one over the other.

Physiotherapists, especially in the field of traumatology, usually recommend some kind of physical exercise for RC tendinopathy [40]. These include scapular proprioceptive exercises and those specific to the RC [40]. In a survey of 502 physiotherapists [40], the most commonly used type of exercise was isometric $(60.2 \%)$. Isometric exercises proposed by Rio et al. [41,42] for patellar tendinopathy were extrapolated to the other tendons [43]. This type of muscle contraction was considered by none of the studies included despite its relevance.

Exercise in general is an effective therapy for shoulder pain [44] and particularly for RC tendinopathy [17], as stated in the introduction. According to the continuum model of tendinopathy of Cook et al. [7,13], exercise is the key treatment for this pathology because it produces cellular and structural changes [45-49]. However, it is not known which muscle development-based exercise programme is best for RC tendinopathy due to the wide variety of exercise methods used at present based on this review. Furthermore, these results are in line with those presented in the systematic review of Littlewood et al. in 2015 [44], where there was no scientific evidence on the most appropriate parameters to apply in active exercises. This, in turn, implied that the studies used different types and parameters of exercises, making it difficult or impossible to compare their efficacy and to carry out meta-analyses.

Passive stretching is quite often included in muscle-development exercise programmes as a final relaxation, so it was allowed in this review-based exclusively on muscle- development physical exercise programmes. This type of stretching is effective in pathologies such as osteoarthritis [50] or rheumatoid arthritis [51]. However, when it is combined with other therapies such as muscle development or balance, together with the methodological limitations of some studies [52,53], their usefulness in active exercise programmes could be questioned. 
There are three areas in terms of how the tendons adapt to load [54]: the absence of load area and the excessive load area, resulting in a maladaptive response of the tendon with increased degradation of collagen, as well as a third adequate load area, where homeostasis and functional adaptation of the tendon are maintained. Again, based on the model proposed by Cook et al. [7,13], and taking into account the load progression model for Achilles and patellar tendinopathy [55], it is established that each patient has a specific load tolerance evaluated with a specific load test. This particularity enabled the thought that more scientific evidence should be generated on how the appropriate load is assessed and managed, rather than looking for a specific exercise. Exercise will be beneficial or not depending on how hard the patient finds it, and could be one of the reasons why no differences are found when comparing several types of physical exercise.

Following the background, different muscle-development exercises could be used for not establishing the adequate therapeutic objectives according to each aetiopathology, among other reasons [56]. For example, some studies used the term "subacromial syndrome", as they understood the "subacromial impact" to be the cause of the clinical problem. However, overuse is actually considered the cause of the tendinopathy [57]. Therefore, this term should not be used to avoid confusion and to agree on a common language [57]. This fact leads to the criteria used by researchers for inclusion of study subjects. In this regard, it should be noted that the articles analysed in this review considered similar inclusion criteria. However, the majority $(87.5 \%)$ used orthopaedic tests, such as the Neer or Hawkins-Kennedy test, which show poor specificity and lack of diagnostic validity for subacromial impingement syndrome [58,59]. These tests aim to isolate a specific structure of the shoulder. For example, the empty can test and the full can test [60] focus their attention on the supraspinatus tendon and muscle [61]. In contrast, anatomical and histological dissections show the interlocking nature of the RC tendons and their relationship with the capsule, ligament and bursa [62]. Furthermore, this argument is supported by the fact that, during the empty can test and the full can test, the supraspinatus is not specifically activated, but when these tests are being performed, up to nine and eight muscles, respectively, are activated [63]. Therefore, it should not be expected that a specific structure is isolated by this type of test. Simplifying shoulder pain to a structure is a very reductionist approach that does not take into account other factors that may influence it, for example, depression, anxiety or insomnia [64], because no nociception is needed to generate pain [61].

Regarding methodology, a large part of the papers that analyse exercise combine it with other therapies [65-68], which makes it difficult to know the real effect of exercise. Thus, other therapies were excluded in this review. Additionally, these were studies of poor methodological quality [69-71], so no solid conclusions can be drawn. To verify this last point, the use of methodological quality tools from the selected studies is highly recommended [30,32]. According to recent studies [72,73], PEDro and CROB are considered valid and useful methods for assessing RCTs. PEDro covers more items than CROB, although six of them are common, which makes the content similar [72]. Despite the aim of both of them being common and their content similar, they should not be used interchangeably due to the low convergent validity of their summary scores and of some individual items [72].

Furthermore, there is currently no consensus about the most appropriate choice between the methods mentioned [73], so more research is necessary to evaluate the best option for each case. Regarding physiotherapeutic interventions, as is the case at hand, PEDro (1999) was designed and recommended especially for them [74,75], although there are authors who advise against it, as it provides a global score that aggregates heterogeneous items, which can mask interest biases [76,77]. By contrast, CROB, created in 2011 [73], evaluates fewer domains, but does so in an isolated way [32,78]. In addition, despite it also offering a global interpretation, it is not based on aggregating points, but taking into account whether the biases produced, i.e., items negatively scored could have a significant impact on the results or conclusions of the study [78], i.e., risk of material bias. Thus, CROB involves a clear subjectivity component regarding the reviewer, which differentiates it 
from PEDro, and which has led researchers, among other factors, to a lack of consensus regarding best method.

The authors of this study, after evaluating expert opinions, decided to include PEDro and $\mathrm{CROB}$, not only to evaluate the possible biases of the selected studies, but to compare the global interpretation of the results of both of them: good (PEDro) and low risk of bias (CROB). Although these global data were consistent among them, some items need to be discussed individually. In this sense, it is interesting that the intrinsic nature of physiotherapy interventions often makes it difficult to blind both patients and the physiotherapists assisting them. This means that scoring of clinical trials using scales of methodological quality that consider blinding, such as the PEDro and the CROB, has this initial handicap, as opposed to other clinical settings. That could be why none of the RCTs analysed used a placebo group to assess the impact of the intervention $[79,80]$. This fact became clear in our results. Although the three items related to blinding in PEDro are objective and easy to evaluate (Yes/No), the two in CROB led us to wonder if their non-compliance would imply a global interpretation of "unclear risk of bias" and not the established one, "low risk of bias". On the one hand, this reflection becomes more important when knowing that one of the variables considered was pain and that patients blinding in these cases is considered essential $[81,82]$. However, the interventions considered in this study were based on physical exercises, without the use of placebo control groups in any case. Both groups did exercises that were beneficial for shoulder pain and function, as the results showed. This fact made user blinding, and even that of the professional, less important. Therefore, we consider that the conclusions would not have been different with double blinding. Regarding the "blinding of outcome assessment", which three articles did not comply with, we observed that most of the results were objective, quantifiable and therefore not modifiable by the evaluator. For example, PROMs, goniometers, inclinometers and digital dynamometers are assessment tools that provide numerical results. Few authors used manual goniometers, which imply a certain subjectivity, but, when used correctly by experts, minimise bias $[83,84]$. In addition to the reasons mentioned, [32] states that when blinding is not feasible in a trial, its quality should not be considered low.

On the other hand, we valued the "random sequence generation" item as very important in these interventions, which was met by all studies, as it was one of the inclusion criteria for the systematic review.

To conclude the discussion on the assessment of methodological quality, based on the justifications stated above, the authors decided on the "low risk of bias" interpretation of the CROB, but with some caution due to its tendency towards "unclear risk of bias", unlike the clear "good" result obtained with PEDro. Likewise, this review advocates presenting the global results of any assessment of methodological quality, and the individual data of each item, as recommended by [32], as well as a summary that describes the most notable aspects and even a justification of the subjective substantial decisions, which, as is the case for the CROB, need to be made.

The studied interventions lasted from 4 to 12 weeks. In this regard, there is evidence of an improvement in strength and in the area of the muscular cross section in a period of 2 to 4 weeks [85,86]. Authors such as Fridén [87] have established that, specifically, eccentric training requires 8 weeks to generate structural alterations in the skeletal muscle. Therefore, the question is whether a period of 4 weeks of training is enough to generate useful changes in the recovery process as proposed by Vallés-Carrascosa et al. [22].

Regarding the outcome, the measures used most often to assess patient perception in this review are PROMs. These questionnaires, with subjective connotations, are increasingly frequent in the scientific literature on shoulder studies [88]. In this regard, Mosher et al. [88] established that the most widely used were the "American Shoulder and Elbow Surgeons Shoulder Score", "Oxford Shoulder Score" and "Visual Analogue Scales". However, the tools considered most often in this research were NPRS or VAS for pain, and SPADI and WORC for function and pain. Communication during a therapeutic process between clinicians and patients tends to focus on the latter. Therefore, it not only encompasses objectivity, but 
also involves users' feelings, ideas, concerns and experience about their health condition, i.e., more subjective aspects [89]. Clinicians should know both the patients and their context to generate a therapeutic alliance and, consequently, improve treatment adherence, even more so if it is active physical exercise [90]. Using these measurement systems encourages patients to participate more actively in their treatment through self-assessment of pain [91], function [92] or fear [93], among others.

One of the strengths of this study is that it involved an extensive literature search in six databases with no time limit. RCTs were only included to achieve the highest level of evidence possible in clinical trials, as well as to ensure a low risk of bias in the methodology. All studies were scored on the PEDro scale of good methodological quality, and a minimum of 6 points was required in the inclusion criteria. This review presents a qualitative analysis of active exercise programmes that increase muscle tone in order to improve pain and function in the shoulders with RC tendinopathy. Secondarily, the approach of the studies focuses on patient perception of their own pain and function.

Regarding limitations, the studies included used highly variable sample sizes, and some did not even calculate the sample size. The heterogeneity of muscle development exercise programmes did not allow to compare them globally due to the different doses of the intervention and different methodology of the exercises applied. Even so, the authors of this study attempted to complement the systematic review with quantitative analysis by group of studies. However, only two or three studies out of eight could be compared in each of the seven individual meta-analyses conducted regarding pain, strength (ABD, IR, $\mathrm{ER}), \mathrm{ROM}$ in shoulder flexion and disability. The lack of homogeneity of the interventions implied insufficient data to generate general conclusions. Additionally, with such a small number of compared studies, one of them had a weight over $90 \%$, which proved the decisive influence the results. The above factors resulted in poor and inconclusive results in favour of eccentric training. Therefore, the inclusion of quantitative analyses in this paper was discarded. This limitation leads us to prospectively consider the meta-analysis of future homogeneous interventions that may be published.

The authors also propose studies that apply exclusively homogeneous exercise programmes and parameters, i.e., without combining them with other therapies to assess their real effectiveness. Therefore, the systematic reviews could be also complemented with comprehensive meta-analyses. Given the response of the tendinopathies to the load, scientific evidence should be generated on how this load is evaluated and managed in RC tendinopathy patients.

After analysing and comparing different active physical exercise programmes in good methodological quality studies, this review, similar to many other studies [17-20], argues that these programmes could be applied to improve pain and function in RC tendinopathy patients, without highlighting the efficacy of one over the other. Also worth mentioning is the assessment of patients perception of the improvement achieved with the therapies.

\section{Conclusions}

All the physical exercise programmes based exclusively on muscle development covered by this systematic review were effective in the treatment of rotator cuff tendinopathy with the aim of improving shoulder pain and function. However, no solid results were obtained when the different interventions were compared due to their heterogeneity. Only one study found statistically and clinically significant differences in favour of eccentric training compared to a conventional exercise programme, i.e., global shoulder exercises, assessed using the Western Ontario Rotator Cuff index questionnaire.

The review considered exercise programmes based on isolated eccentric contractions, combinations of concentric and eccentric contractions, and isolated concentric contractions, ordered from most to least frequent. The exercises consisted of: open and closed kinetic chain exercise programmes, activities with and without coactivation of the glenohumeral muscles, global shoulder exercises, exercises with high eccentric loads, and supervised 
activities in consultation or at home without supervision. The interventions lasted 4, 6, 8 and 12 weeks, with follow-up up to week 26 from the start of the intervention.

Tools used to measure patients' perception featured far more than other, more objective measuring instruments such as dynamometers, inclinometers or goniometers. The most widely used Patients Related Outcome Measures were the Numeric Rating Scale and Visual Analogue Scale for pain, as well as Shoulder Pain and Disabilities Index and Western Ontario Rotator Cuff index for pain and function. As a clinical contribution, we would like to highlight the benefits of actively involving the user in physiotherapy to ensure greater adherence to treatment.

Finally, based on the referenced literature, it is recommended that attention be focused on the appropriate amount of load to be applied, rather than on the method of physical exercise used.

Author Contributions: J.G.D.-R. and G.C.-M. conceptualised the idea. J.G.D.-R., G.C.-M., J.J.J.-R. and C.R.-F. carried out the study selection, data extraction and manuscript drafting. J.G.D.-R., G.C.-M., J.J.J.-R. and C.R.-F. have been involved in critically revising for important intellectual contents. All authors contributed to the final version and approved the final paper for publication. All authors have read and agreed to the published version of the manuscript.

Funding: This research received no external funding.

Institutional Review Board Statement: Not applicable.

Informed Consent Statement: Not applicable.

Acknowledgments: The authors would like to thank the Research Group "Area of Physiotherapy" CTS-305 at the University of Seville.

Conflicts of Interest: The authors declare no conflict of interest.

\section{Abbreviations}

$\begin{array}{ll}\text { ABD } & \text { Abduction } \\ \text { AHD } & \text { Acromio-Humeral Distance } \\ \text { AROM } & \text { Active Range of Motion } \\ \text { CI } & \text { Confidence Interval } \\ \text { CM } & \text { Constant Murlay } \\ \text { CROB } & \text { Cochrane Risk of Bias } \\ \text { DASH } & \text { Disabilities of Arm, Shoulder and Hand } \\ \text { EMG } & \text { Electromyography } \\ \text { ER } & \text { External Rotation } \\ \text { FABQ } & \text { Fear Avoidance Beliefs Questionnaire } \\ \text { GROC } & \text { Global Rating of Change } \\ \text { IR } & \text { Internal Rotation } \\ \text { MeSH } & \text { Medical Subject Headings } \\ \text { MR } & \text { Maximum Repetition } \\ \text { MD } & \text { Mean Difference } \\ \text { MDC } & \text { Minimum Detectable Change } \\ \text { MDP } & \text { Muscle Development Program } \\ \text { NPRS } & \text { Numeric Pain Rating Scale } \\ \text { OCEBM } & \text { Oxford Centre for Evidence-Based Medicine } \\ \text { OSI } & \text { Ocupational Stress Indicator } \\ \text { PROMs } & \text { Patient Related Outcome Measures } \\ \text { RC } & \text { Rotator Cuff } \\ \text { RCT } & \text { Randomized Controlled Trial } \\ \text { RHB } & \text { Rehabilitation } \\ \text { ROM } & \text { Range of Motion } \\ \text { SD } & \text { Standard Desviation } \\ \text { SE } & \text { Standard Error }\end{array}$


SMD Standarized Mean Difference

SPADI Shoulder Pain and Disabilities Index

UQYBT Upper Quarter Y-Balance test

VAS Visual Analogue Scale

WORC Western Ontario Rotator Cuff Index

\section{Appendix A}

Table A1. Search strategy terms ordered by meaning.

\section{MeSH Terms * and Others}

Identifier

tendinopathy or tendonopathy or tendinosis or tendinoses or tendonosis or tendonoses or tendinitis or tendinitides or tendonitis or tendonitides or "shoulder tendinopathy" or "shoulder impingement syndrome" or "shoulder impingement" or "subacromial impingement syndrome" or "subacromial bursitis"

\begin{tabular}{ll}
\hline $\begin{array}{l}\text { "rotator cuff" or supraspinatus or infraspinatus or subscapularis or "teres minor" } \\
\text { or "long head of biceps" }\end{array}$ & $\mathbf{2}$ \\
\hline $\begin{array}{l}\text { "isometric contraction" or "isotonic contraction" or concentric* or eccentric * or } \\
\text { exercise* or resistance* or load * }\end{array}$ & $\mathbf{3}$ \\
\hline "randomized controlled trial" & 4 \\
\hline
\end{tabular}
${ }^{*} \mathrm{MeSH}$ terms are in italics.

\section{Appendix B}

Table A2. Search strategy in the different databases.

\begin{tabular}{|c|c|c|}
\hline Database & Search Strategy & Identifier \\
\hline Pubmed & $\begin{array}{l}\text { (tendin * or tendon * or "shoulder tendinopathy" or "shoulder } \\
\text { impingement *" or "shoulder burs *" or "subacromial impingement" or } \\
\text { "subacromial impingement *" or "subacromial bursitis") and ("rotator cuff" } \\
\text { or supraspinatus or infraspinatus or subscapularis or "teres minor" or "long } \\
\text { head of bíceps") and (isometric * or isotonic * or concentric* or eccentric * or } \\
\text { exercise * or "resistance training" or load *) } \\
\text { Filter: "clinical trial" }\end{array}$ & 1,2 and 3 \\
\hline WOS & $\begin{array}{l}\text { (tendin * or tendon * or "shoulder tendinopathy" or "shoulder } \\
\text { impingement *" or "shoulder burs" or "subacromial impingement" or } \\
\text { "subacromial impingement*" or "subacromial bursitis") and ("rotator cuff" } \\
\text { or supraspinatus or infraspinatus or subscapularis or "teres minor" or "long } \\
\text { head of biceps") and (isometric * or isotonic * or concentric* or eccentric * or } \\
\text { exercise * or resistance * or load *) and random * } \\
\text { Filter: "article" }\end{array}$ & $1,2,3$ and 4 \\
\hline PEDro & $\begin{array}{l}\text { "rotator cuff tend *" and "strength training" and pain and "upper arm, } \\
\text { shoulder or shoulder girdle" and musculoskeletal and "clinical trial" }\end{array}$ & 1 and $2 *$ \\
\hline Cinahl & $\begin{array}{l}\text { (tendin * or tendon * or "shoulder tendinopathy" or "shoulder } \\
\text { impingement *" or "shoulder burs" or "subacromial impingement" or } \\
\text { "subacromial impingement*" or "subacromial bursitis") and ("rotator cuff" } \\
\text { or supraspinatus or infraspinatus or subscapularis or "teres minor" or "long } \\
\text { head of bíceps") and (isometric * or isotonic * or concentric* or eccentric * or } \\
\text { exercise * or "resistance training" or load *) } \\
\text { Filter: "clinical trial" }\end{array}$ & 1,2 and 3 \\
\hline Scopus & $\begin{array}{l}\text { (tendin * or tendon * or "shoulder tendinopathy" or "shoulder } \\
\text { impingement *" or "shoulder burs" or "subacromial impingement" or } \\
\text { "subacromial impingement" or "subacromial bursitis") and ("rotator cuff" } \\
\text { or supraspinatus or infraspinatus or subscapularis or "teres minor" or "long } \\
\text { head of biceps") and (isometric* or isotonic * or concentric* or eccentric* or } \\
\text { exercise * or "resistance training" or load *) and random * } \\
\text { Filter: "article" }\end{array}$ & $1,2,3$ and 4 \\
\hline
\end{tabular}


Table A2. Cont.

\begin{tabular}{|c|c|c|}
\hline Database & Search Strategy & Identifier \\
\hline Dialnet $* *$ & $\begin{array}{l}\text { (tendin * or tendon * or "shoulder tendinopathy" or "shoulder } \\
\text { impingement *" or "shoulder burs *" or "subacromial impingement" or } \\
\text { "subacromial impingement" or "subacromial bursitis") AND (isometric * } \\
\text { or isotonic * or concentric * or eccentric * or exercise * or "resistance } \\
\text { training" or load *) and random * } \\
\text { "rotator cuff" or supraspinatus or infraspinatus or subscapularis or "teres } \\
\text { minor" or "long head of biceps") and (isometric * or isotonic * or concentric } \\
\text { * or eccentric * or exercise* or "resistance training" or load *) and random * } \\
\text { Filter: "artículos de revista" }\end{array}$ & $1,2,3$ and 4 \\
\hline
\end{tabular}

\section{References}

1. Littlewood, C. Contractile Dysfunction of the Shoulder (Rotator Cuff Tendinopathy): An Overview. J. Man. Manip. Ther. 2012, 20, 209-213. [CrossRef] [PubMed]

2. Pope, D.P.; Croft, P.R.; Pritchard, C.M.; Silman, A.J. Prevalence of Shoulder Pain in the Community: The Influence of Case Definition. Ann. Rheum. Dis. 1997, 56, 308-312. [CrossRef] [PubMed]

3. Van der Windt, D.A.; Koes, B.W.; de Jong, B.A.; Bouter, L.M. Shoulder Disorders in General Practice: Incidence, Patient Characteristics, and Management. Ann. Rheum. Dis. 1995, 54, 959-964. [CrossRef] [PubMed]

4. Redondo-Alonso, L.; Chamorro-Moriana, G.; Jimenez-Rejano, J.J.; Lopez-Tarrida, P.; Ridao-Fernandez, C. Relationship between Chronic Pathologies of the Supraspinatus Tendon and the Long Head of the Biceps Tendon: Systematic Review. BMC Musculoskelet. Disord. 2014, 15, 1-10. [CrossRef] [PubMed]

5. Longo, U.G.; Loppini, M.; Marineo, G.; Khan, W.S.; Maffulli, N.; Denaro, V. Tendinopathy of the Tendon of the Long Head of the Biceps. Sports Med. Arthrosc. Rev. 2021, 19, 321-332. [CrossRef]

6. Gimbel, J.A.; Van Kleunen, J.P.; Mehta, S.; Perry, S.M.; Williams, G.R.; Soslowsky, L.J. Supraspinatus Tendon Organizational and Mechanical Properties in a Chronic Rotator Cuff Tear Animal Model. J. Biomech. 2004, 37, 739-749. [CrossRef]

7. Cook, J.L.; Purdam, C.R. Is Tendon Pathology a Continuum? A Pathology Model to Explain the Clinical Presentation of Load-Induced Tendinopathy. Br. J. Sports Med. 2009, 43, 409-416. [CrossRef]

8. Scott, A.; Squier, K.; Alfredson, H.; Bahr, R.; Cook, J.L.; Coombes, B.; De Vos, R.J.; Fu, S.N.; Grimaldi, A.; Lewis, J.S.; et al. ICON 2019: International Scientific Tendinopathy Symposium Consensus: Clinical Terminology. Br. J. Sports Med. 2020, 54, $260-262$. [CrossRef]

9. Linaker, C.H.; Walker-Bone, K. Shoulder Disorders and Occupation. Best Pract. Res. Clin. Rheumatol. 2015, 19, 405-423. [CrossRef]

10. Bartolozzi, A.; Andreychik, D.; Ahmad, S. Determinants of Outcome in the Treatment of Rotator Cuff Disease. Clin. Orthop. Relat. Res. 1994, 308, 90-97. [CrossRef]

11. Lewis, J.S. Rotator Cuff Tendinopathy. Br. J. Sports Med. 2009, 43, 236-241. [CrossRef] [PubMed]

12. Lewis, J.S. Rotator Cuff Tendinopathy: A Model for the Continuum of Pathology and Related Management. Br. J. Sports Med. 2010, 44, 918-923. [CrossRef] [PubMed]

13. Cook, J.L.; Rio, E.; Purdam, C.R.; Docking, S.I. Revisiting the Continuum Model of Tendon Pathology: What Is Its Merit in Clinical Practice and Research? Br. J. Sports Med. 2016, 50, 1187-1191. [CrossRef] [PubMed]

14. Croisier, J.L.; Foidart-Dessalle, M.; Tinant, F.; Crielaard, J.M.; Forthomme, B. An Isokinetic Eccentric Programme for the Management of Chronic Lateral Epicondylar Tendinopathy. Br. J. Sports Med. 2007, 41, 269-275. [CrossRef] [PubMed]

15. Wilson, F.; Walshe, M.; O’Dwyer, T.; Bennett, K.; Mockler, D.; Bleakley, C. Exercise, Orthoses and Splinting for Treating Achilles Tendinopathy: A Systematic Review with Meta-Analysis. Br. J. Sports Med. 2018, 52, 1564-1574. [CrossRef]

16. Lim, H.Y.; Wong, S.H. Effects of Isometric, Eccentric, or Heavy Slow Resistance Exercises on Pain and Function in Individuals with Patellar Tendinopathy: A Systematic Review. Physiother. Res. Int. 2018, 23, e1721. [CrossRef] [PubMed]

17. Littlewood, C.; Ashton, J.; Chance-Larsen, K.; May, S.; Sturrock, B. Exercise for Rotator Cuff Tendinopathy: A Systematic Review. Physiotherapy 2012, 98, 101-109. [CrossRef] [PubMed]

18. Kuhn, J.E. Exercise in the Treatment of Rotator Cuff Impingement: A Systematic Review and a Synthesized Evidence-Based Rehabilitation Protocol. J. Shoulder Elb. Surg. 2009, 18, 138-160. [CrossRef]

19. Hanratty, C.E.; McVeigh, J.G.; Kerr, D.P.; Basford, J.R.; Finch, M.B.; Pendleton, A.; Sim, J. The Effectiveness of Physiotherapy Exercises in Subacromial Impingement Syndrome: A Systematic Review and Meta-Analysis. Semin. Arthritis Rheum. 2012, 42, 297-316. [CrossRef]

20. Desmeules, F.; Boudreault, J.; Dionne, C.E.; Frémont, P.; Lowry, V.; MacDermid, J.C.; Roy, J.S. Efficacy of Exercise Therapy in Workers with Rotator Cuff Tendinopathy: A Systematic Review. J. Occup. Health 2016, 58, 389-403. [CrossRef]

21. Ingwersen, K.G.; Vobbe, J.W.; Pedersen, L.L.; Sørensen, L.; Wedderkopp, N. Effect of Psychomotricity in Combination With 3 Months of Active Shoulder Exercises in Individuals with Chronic Shoulder Pain: Primary Results From an Investigator-Blinded, Randomized, Controlled Trial. Arch. Phys. Med. Rehabil. 2019, 100, 2136-2143. [CrossRef] 
22. Vallés-Carrascosa, E.; Gallego-Izquierdo, T.; Jiménez-Rejano, J.J.; Plaza-Manzano, G.; Pecos-Martín, D.; Hita-Contreras, F.; Achalandabaso-Ochoa, A. Pain, Motion and Function Comparison of Two Exercise Protocols for the Rotator Cuff and Scapular Stabilizers in Patients with Subacromial Syndrome [with Consumer Summary]. J. Hand Ther. 2018, 31, 227-237. [CrossRef]

23. Heron, S.R.; Woby, S.R.; Thompson, D.P. Comparison of Three Types of Exercise in the Treatment of Rotator Cuff Tendinopathy/Shoulder Impingement Syndrome: A Randomized Controlled Trial. Physiotherapy 2017, 103, 167-173. [CrossRef] [PubMed]

24. Dejaco, B.; Habets, B.; van Loon, C.; van Grinsven, S.; van Cingel, R. Eccentric versus Conventional Exercise Therapy in Patients with Rotator Cuff Tendinopathy: A Randomized, Single Blinded, Clinical Trial. Knee Surg. Sport. Traumatol. Arthrosc. 2017, 25, 2051-2059. [CrossRef]

25. Desmeules, F.; Côté, C.H.; Frémont, P. Therapeutic Exercise and Orthopedic Manual Therapy for Impingement Syndrome: A Systematic Review. Clin. J. Sport Med. 2003, 13, 176-182. [CrossRef] [PubMed]

26. Grant, H.J.; Arthur, A.; Pichora, D.R. Evaluation of Interventions for Rotator Cuff Pathology: A Systematic Review. J. Hand Ther. 2004, 17, 274-299. [CrossRef] [PubMed]

27. Johansson, K.; Öberg, B.; Adolfsson, L.; Foldevi, M. A Combination of Systematic Review and Clinicians' Beliefs in Interventions for Subacromial Pain. Br. J. Gen. Pract. 2002, 52, 145-152.

28. Kelly, S.M.; Wrightson, P.A.; Meads, C.A. Clinical Outcomes of Exercise in the Management of Subacromial Impingement Syndrome: A Systematic Review. Clin. Rehabil. 2010, 24, 99-109. [CrossRef]

29. Moher, D.; Liberati, A.; Tetzlaff, J.; Altman, D.G.; Grp, P. Preferred Reporting Items for Systematic Reviews and Meta-Analyses: The PRISMA Statement (Reprinted from Annals of Internal Medicine). Phys. Ther. 2009, 89, 873-880. [CrossRef]

30. Yamato, T.P.; Maher, C.; Koes, B.; Moseley, A. The PEDro Scale Had Acceptably High Convergent Validity, Construct Validity, and Interrater Reliability in Evaluating Methodological Quality of Pharmaceutical Trials. J. Clin. Epidemiol. 2017, 86, 176-181. [CrossRef] [PubMed]

31. Verhagen, A.P.; De Vet, H.C.W.; De Bie, R.A.; Kessels, A.G.H.; Boers, M.; Bouter, L.M.; Knipschild, P.G. The Delphi List: A Criteria List for Quality Assessment of Randomized Clinical Trials for Conducting Systematic Reviews Developed by Delphi Consensus. J. Clin. Epidemiol. 1998, 51, 1235-1241. [CrossRef]

32. Higgins, J.P.T.; Altman, D.G.; Gøtzsche, P.C.; Jüni, P.; Moher, D.; Oxman, A.D.; Savović, J.; Schulz, K.F.; Weeks, L.; Sterne, J.A.C. The Cochrane Collaboration's Tool for Assessing Risk of Bias in Randomised Trials. BMJ 2011, 343. [CrossRef] [PubMed]

33. Maenhout, A.G.; Mahieu, N.N.; De Muynck, M.; De Wilde, L.F.; Cools, A.M. Does Adding Heavy Load Eccentric Training to Rehabilitation of Patients with Unilateral Subacromial Impingement Result in Better Outcome? A Randomized, Clinical Trial. Knee Surg. Sport. Traumatol. Arthrosc. 2013, 21, 1158-1167. [CrossRef] [PubMed]

34. Blume, C.; Wang-Price, S.; Trudelle-Jackson, E.; Ortiz, A. Comparison of eccentric and concentric exercise interventions in adults with subacromial impingement syndrome. Int. J. Sports Phys. Ther. 2015, 10, 441-455. [PubMed]

35. Granviken, F.; Vasseljen, O. Home Exercises and Supervised Exercises Are Similarly Effective for People with Subacromial Impingement: A Randomised Trial. J. Physiother. 2015, 61, 135-141. [CrossRef]

36. Chaconas, E.J.; Kolber, M.J.; Hanney, W.J.; Daugherty, M.L.; Wilson, S.H.; Sheets, C. Shoulder external rotator eccentric training versus general shoulder exercise for subacromial pain syndrome: A randomized controlled trial. Int. J. Sports Phys. Ther. 2017, 12, 1121-1133. [CrossRef]

37. Boudreau, N.; Gaudreault, N.; Roy, J.-S.S.; Bédard, S.; Balg, F.F.F.; Bedard, S.; Balg, F.F.F. The Addition of Glenohumeral Adductor Coactivation to a Rotator Cuff Exercise Program for Rotator Cuff Tendinopathy: A Single-Blind Randomized Controlled Trial. J. Orthop. Sport. Phys. Ther. 2019, 49, 126. [CrossRef]

38. Manterola, C.; Asenjo-Lobos, C.; Otzen, T. Hierarchy of Evidence. Levels of Evidence and Grades of Recommendation from Current Use. Rev. Chil. Infectol. 2014, 31, 705-718. [CrossRef]

39. Martins, L.V.; Marziale, M.H.P. Assessment of Proprioceptive Exercises in the Treatment of Rotator Cuff Disorders in Nursing Professionals: A Randomized Controlled Clinical Trial. Braz. J. Phys. Ther. 2012, 16, 502-509. [CrossRef]

40. Smythe, A.; White, J.; Littlewood, C.; Bury, J.; Haines, T.; Malliaras, P. Physiotherapists Deliver Management Broadly Consistent with Recommended Practice in Rotator Cuff Tendinopathy: An Observational Study. Musculoskelet. Sci. Pract. 2020, $47,102132$. [CrossRef]

41. Rio, E.; Van Ark, M.; Docking, S.; Moseley, G.L.; Kidgell, D.; Gaida, J.E.; Van Den Akker-Scheek, I.; Zwerver, J.; Cook, J. Isometric Contractions Are More Analgesic than Isotonic Contractions for Patellar Tendon Pain: An in-Season Randomized Clinical Trial. Clin. J. Sport Med. 2017, 27, 253-259. [CrossRef]

42. Rio, E.; Kidgell, D.; Purdam, C.; Gaida, J.; Moseley, G.L.; Pearce, A.J.; Cook, J. Isometric Exercise Induces Analgesia and Reduces Inhibition in Patellar Tendinopathy. Br. J. Sports Med. 2015, 49, 1277-1283. [CrossRef]

43. Gravare Silbernagel, K.; Vicenzino, B.T.; Rathleff, M.S.; Thorborg, K. Isometric Exercise for Acute Pain Relief: Is It Relevant in Tendinopathy Management? Br. J. Sports Med. 2019, 53, 1330-1331. [CrossRef]

44. Littlewood, C.; Malliaras, P.; Chance-Larsen, K. Therapeutic Exercise for Rotator Cuff Tendinopathy: A Systematic Review of Contextual Factors and Prescription Parameters. Int. J. Rehabil. Res. 2015, 38, 95-106. [CrossRef]

45. Langberg, H.; Ellingsgaard, H.; Madsen, T.; Jansson, J.; Magnusson, S.P.; Aagaard, P.; Kjær, M. Eccentric Rehabilitation Exercise Increases Peritendinous Type I Collagen Synthesis in Humans with Achilles Tendinosis. Scand. J. Med. Sci. Sport. 2007, 17, 61-66. [CrossRef] [PubMed] 
46. Shalabi, A.; Kristoffersen-Wilberg, M.; Svensson, L.; Aspelin, P.; Movin, T. Eccentric Training of the Gastrocnemius-Soleus Complex Ion Chronic Achilles Tendinopathy Results in Decreased Tendon Volume and Intratendinous Signal as Evaluated by MRI. Am. J. Sports Med. 2004, 32, 1286-1296. [CrossRef] [PubMed]

47. Öhberg, L.; Lorentzon, R.; Alfredson, H. Eccentric Training in Patients with Chronic Achilles Tendinosis: Normalised Tendon Structure and Decreased Thickness at Follow Up. Br. J. Sports Med. 2004, 38, 8-11. [CrossRef] [PubMed]

48. Öhberg, L.; Alfredson, H. Effects on Neovascularisation behind the Good Results with Eccentric Training in Chronic Mid-Portion Achilles Tendinosis? Knee Surg. Sport. Traumatol. Arthrosc. 2004, 12, 465-470. [CrossRef]

49. Roos, E.M.; Engström, M.; Lagerquist, A.; Söderberg, B. Clinical Improvement after 6 Weeks of Eccentric Exercise in Patients with Mid-Portion Achilles Tendinopathy-A Randomized Trial with 1-Year Follow-Up. Scand. J. Med. Sci. Sport. 2004, 14, 286-295. [CrossRef] [PubMed]

50. De Mattos, F.; Leite, N.; Pitta, A.; Bento, P.C.B. Effects of Aquatic Exercise on Muscle Strength and Functional Performance of Individuals with Osteoarthritis: A Systematic Review. Rev. Bras. Reumatol. Engl. Ed. 2016, 56, 530-542. [CrossRef]

51. Williams, M.A.; Williamson, E.M.; Heine, P.J.; Nichols, V.; Glover, M.J.; Dritsaki, M.; Adams, J.; Dosanjh, S.; Underwood, M.; Rahman, A.; et al. Strengthening and Stretching for Rheumatoid Arthritis of the Hand (SARAH). A Randomised Controlled Trial and Economic Evaluation. Health Technol. Assess. (Rockv). 2015, 19, 221. [CrossRef] [PubMed]

52. de Lorena, S.B.; de Lima, M.d.C.C.; Ranzolin, A.; Duarte, Â.L.B.P. Effects of Muscle Stretching Exercises in the Treatment of Fibromyalgia: A Systematic Review. Revista Bras. Reumatol. 2015, 55, 167-173. [CrossRef]

53. Mine, K.; Nakayama, T.; Milanese, S.; Grimmer, K. Effectiveness of Stretching on Posterior Shoulder Tightness and Glenohumeral Internal-Rotation Deficit: A Systematic Review of Randomized Controlled Trials. J. Sport Rehabil. 2017, 26, 294-305. [CrossRef] [PubMed]

54. Docking, S.I.; Cook, J. How Do Tendons Adapt? Going Beyond Tissue Responses to Understand Positive Adaptation and Pathology Development: A Narrative Review-PubMed. J. Musculoskelet. Neuronal Interact. 2019, 19, 300-310. [PubMed]

55. Mascaró, A.; Cos, M.À.; Morral, A.; Roig, A.; Purdam, C.; Cook, J. Load Management in Tendinopathy: Clinical Progression for Achilles and Patellar Tendinopathy. Apunt. Med. L'esport 2018, 53, 19-27. [CrossRef]

56. Cloke, D.J.; Watson, H.; Purdy, S.; Steen, I.N.; Williams, J.R. A Pilot Randomized, Controlled Trial of Treatment for Painful Arc of the Shoulder. J. Shoulder Elb. Surg. 2008, 17, 17-21. [CrossRef] [PubMed]

57. Dhillon, K.S. Subacromial Impingement Syndrome of the Shoulder: A Musculoskeletal Disorder or a Medical Myth? Malays. Orthop. J. 2019, 13, 1-7.

58. Hegedus, E.J.; Goode, A.; Campbell, S.; Morin, A.; Tamaddoni, M.; Moorman, C.T.; Cook, C. Physical Examination Tests of the Shoulder: A Systematic Review with Meta-Analysis of Individual Tests. Br. J. Sports Med. 2008, 42, 80-92. [CrossRef]

59. Papadonikolakis, A.; McKenna, M.; Warme, W.; Martin, B.I.; Matsen, F.A. Published Evidence Relevant to the Diagnosis of Impingement Syndrome of the Shoulder. J. Bone Jt. Surg. Ser. A 2011, 93, 1827-1832. [CrossRef]

60. Kelly, B.T.; Kadrmas, W.R.; Speer, K.P. The Manual Muscle Examination for Rotator Cuff Strength: An Electromyographic Investigation. Am. J. Sports Med. 1996, 24, 581-588. [CrossRef]

61. Salamh, P.; Lewis, J. It Is Time to Put 'Special Tests' for Rotator Cuff Related Shoulder Pain Out to Pasture. J. Orthop. Sport. Phys. Ther. 2020, 50, 1-11. [CrossRef] [PubMed]

62. Clark, J.M.; Harryman, D.T. Tendons, Ligaments, and Capsule of the Rotator Cuff. Gross and Microscopic Anatomy-PubMed. J. Bone Jt. Surg. 1992, 74, 713-725. [CrossRef]

63. Boettcher, C.E.; Ginn, K.A.; Cathers, I. The "empty Can" and "Full Can" Tests Do Not Selectively Activate Supraspinatus. J. Sci. Med. Sport 2009, 12, 435-439. [CrossRef] [PubMed]

64. Keung, W.W.; Yan, L.I.M.; Patrick, Y.; Hang, S.; Teng, L.H. The Effect of Psychological Factors on Pain, Function and Quality of Life in Patients with Rotator Cuff Tendinopathy: A Systematic Review. Musculoskelet. Sci. Pract. 2020, 102173. [CrossRef]

65. Holmgren, T.; Bjornsson Hallgren, H.; Oberg, B.; Adolfsson, L.; Johansson, K. Effect of Specific Exercise Strategy on Need for Surgery in Patients with Subacromial Impingement Syndrome: Randomised Controlled Study. BMJ 2012, 344, e787. [CrossRef] [PubMed]

66. Dilek, B.; Gulbahar, S.; Gundogdu, M.; Ergin, B.; Manisali, M.; Ozkan, M.; Akalin, E. Efficacy of Proprioceptive Exercises in Patients with Subacromial Impingement Syndrome. Am. J. Phys. Med. Rehabil. 2016, 95, 169-182. [CrossRef] [PubMed]

67. Struyf, F.; Nijs, J.; Mollekens, S.; Jeurissen, I.; Truijen, S.; Mottram, S.; Meeusen, R. Scapular-Focused Treatment in Patients with Shoulder Impingement Syndrome: A Randomized Clinical Trial. Clin. Rheumatol. 2013, 32, 73-85. [CrossRef]

68. Hallgren, H.C.B.; Holmgren, T.; Öberg, B.; Johansson, K.; Adolfsson, L.E. A Specific Exercise Strategy Reduced the Need for Surgery in Subacromial Pain Patients. Br. J. Sports Med. 2014, 48, 1431-1436. [CrossRef]

69. Bae, Y.H.; Lee, G.C.; Shin, W.S.; Kim, T.H.; Lee, S.M. Effect of Motor Control and Strengthening Exercises on Pain, Function, Strength and the Range of Motion of Patients with Shoulder Impingement Syndrome. J. Phys. Ther. Sci. 2011, $23,687-692$. [CrossRef]

70. Subasi, V.; Toktas, H.; Demirdal, U.S.; Turel, A.; Cakir, T.; Kavuncu, V. Water-Based versus Land-Based Exercise Program for the Management of Shoulder Impingement Syndrome. Turk. Fiz. Tip Ve Rehabil. Derg. Turk. J. Phys. Med. Rehabil. 2012, $58,79-84$.

71. Başkurt, Z.; Başkurt, F.; Gelecek, N.; Özkan, M.H. The Effectiveness of Scapular Stabilization Exercise in the Patients with Subacromial Impingement Syndrome. J. Back Musculoskelet. Rehabil. 2011, 24, 173-179. [CrossRef] 
72. Moseley, A.M.; Rahman, P.; Wells, G.A.; Zadro, J.R.; Sherrington, C.; Toupin-April, K.; Brosseau, L. Agreement between the Cochrane Risk of Bias Tool and Physiotherapy Evidence Database (PEDro) Scale: A Meta-Epidemiological Study of Randomized Controlled Trials of Physical Therapy Interventions. PLoS ONE 2019, 14, e0222770. [CrossRef]

73. Armijo-Olivo, S.; Fuentes, J.; Ospina, M.; Saltaji, H.; Hartling, L. Inconsistency in the Items Included in Tools Used in General Health Research and Physical Therapy to Evaluate the Methodological Quality of Randomized Controlled Trials: A Descriptive Analysis. Bmc Med. Res. Methodol. 2013, 13, 1-19. [CrossRef] [PubMed]

74. Sherrington, C.; Herbert, R.D.; Maher, C.G.; Moseley, A.M. PEDro. A Database of Randomized Trials and Systematic Reviews in Physiotherapy. Man. Ther. 2000, 5, 223-226. [CrossRef]

75. Maher, C.G.; Sherrington, C.; Herbert, R.D.; Moseley, A.M.; Elkins, M. Reliability of the PEDro Scale for Rating Quality of Randomized Controlled Trials. Phys. Ther. 2003, 83, 713-721. [CrossRef] [PubMed]

76. Da Costa, B.R.; Hilfiker, R.; Egger, M. PEDro's Bias: Summary Quality Scores Should Not Be Used in Meta-Analysis. J. Clin. Epidemiol. 2013, 66, 75-77. [CrossRef] [PubMed]

77. Greenland, S. Quality Scores Are Useless and Potentially Misleading Reply to "Re: A Critical Look at Some Popular Analytic Methods". Am. J. Epidemiol. 1994, 140, 300-301. [CrossRef]

78. Cochrane Handbook for Systematic Reviews of Interventions. Cochrane Training. Available online: https://training.cochrane. org/handbook/current (accessed on 4 March 2021).

79. Vase, L.; Wartolowska, K. Pain, Placebo, and Test of Treatment Efficacy: A Narrative Review. Br. J. Anaesth. 2019, 123, e254-e262. [CrossRef]

80. De Deyn, P.P.; D’Hooge, R. Placebos in Clinical Practice and Research. J. Med. Ethics 1996, 22, 140-146. [CrossRef] [PubMed]

81. Savović, J.; Jones, H.E.; Altman, D.G.; Harris, R.J.; Jüni, P.; Pildal, J.; Als-Nielsen, B.; Balk, E.M.; Gluud, C.; Gluud, L.L.; et al. Influence of Reported Study Design Characteristics on Intervention Effect Estimates from Randomized, Controlled Trials. Ann. Intern. Med. 2012, 157, 429-438. [CrossRef] [PubMed]

82. Wood, L.; Egger, M.; Gluud, L.L.; Schulz, K.F.; Jüni, P.; Altman, D.G.; Gluud, C.; Martin, R.M.; Wood, A.J.G.; Sterne, J.A.C. Empirical Evidence of Bias in Treatment Effect Estimates in Controlled Trials with Different Interventions and Outcomes: Meta-Epidemiological Study. BMJ 2008, 336, 601-605. [CrossRef] [PubMed]

83. Boone, D.C.; Azen, S.P.; Lin, C.M.; Spence, C.; Baron, C.; Lee, L. Reliability of Goniometric Measurements. Phys. Ther. 1978, 58, 1355-1360. [CrossRef] [PubMed]

84. Mullaney, M.J.; McHugh, M.P.; Johnson, C.P.; Tyler, T.F. Reliability of Shoulder Range of Motion Comparing a Goniometer to a Digital Level. Physiother. Theory Pract. 2010, 26, 327-333. [CrossRef]

85. Damas, F.; Phillips, S.M.; Lixandrão, M.E.; Vechin, F.C.; Libardi, C.A.; Roschel, H.; Tricoli, V.; Ugrinowitsch, C. Early Resistance Training-Induced Increases in Muscle Cross-Sectional Area Are Concomitant with Edema-Induced Muscle Swelling. Eur. J. Appl. Physiol. 2016, 116, 49-56. [CrossRef] [PubMed]

86. Brook, M.S.; Wilkinson, D.J.; Mitchell, W.K.; Lund, J.N.; Szewczyk, N.J.; Greenhaff, P.L.; Smith, K.; Atherton, P.J. Skeletal Muscle Hypertrophy Adaptations Predominate in the Early Stages of Resistance Exercise Training, Matching Deuterium Oxide-Derived Measures of Muscle Protein Synthesis and Mechanistic Target of Rapamycin Complex 1 Signaling. FASEB J. 2015, 29, $4485-4496$. [CrossRef]

87. Fridén, J. Changes in Human Skeletal Muscle Induced by Long-Term Eccentric Exercise. Cell Tissue Res. 1984, $236,365-372$. [CrossRef]

88. Mosher, Z.A.; Ewing, M.A.; Collins, C.S.; Young, P.G.; Brabston, E.W.; Momaya, A.M.; Tashjian, R.Z.; Ponce, B.A. Usage Trends of Patient-Reported Outcome Measures in Shoulder Literature. J. Am. Acad. Orthop. Surg. 2019, 24, 1-8. [CrossRef]

89. Jawad Hashim, M. Patient-Centered Communication: Basic Skills. Am. Fam. Physician 2017, 95, $29-34$.

90. Babatunde, F.; MacDermid, J.; MacIntyre, N. Characteristics of Therapeutic Alliance in Musculoskeletal Physiotherapy and Occupational Therapy Practice: A Scoping Review of the Literature. Bmc Health Serv. Res. 2017, 17, 1-23.

91. Thong, I.S.K.; Jensen, M.P.; Miró, J.; Tan, G. The Validity of Pain Intensity Measures: What Do the NRS, VAS, VRS, and FPS-R Measure? Scand. J. Pain 2018, 18, 99-107. [CrossRef]

92. Breckenridge, J.D.; McAuley, J.H. Shoulder Pain and Disability Index (SPADI). J. Physiother. 2011, 57, 197. [CrossRef]

93. Kovacs, F.M.; Muriel, A.; Medina, J.M.; Abraira, V.; Castillo Sánchez, M.D.; Jaúregui, J.O. Psychometric Characteristics of the Spanish Version of the FAB Questionnaire. Spine (Phila. Pa. 1976) 2006, 31, 104-110. [CrossRef] [PubMed] 